\title{
THE
}

2-11-2021

\section{Net volatilization of PAHs from the North Pacific to the Arctic Ocean observed by passive sampling}

Haowen Zheng

Minggang Cai

Wenlu Zhao

Mohammed Khairy

Mian Chen

See next page for additional authors

Follow this and additional works at: https://digitalcommons.uri.edu/gsofacpubs

The University of Rhode Island Faculty have made this article openly available.

Please let us know how Open Access to this research benefits you.

This is a pre-publication author manuscript of the final, published article.

Terms of Use

This article is made available under the terms and conditions applicable towards Open Access Policy Articles, as set forth in our Terms of Use.

\section{Citation/Publisher Attribution}

Zheng, H., Cai, M., Zhao, W., Khairy, M., Chen, M., Deng, H., \& Lohmann, R. (2021). Net volatilization of PAHs from the north pacific to the arctic ocean observed by passive sampling. Environmental Pollution, 276. doi:10.1016/j.envpol.2021.116728

This Article is brought to you for free and open access by the Graduate School of Oceanography at DigitalCommons@URI. It has been accepted for inclusion in Graduate School of Oceanography Faculty Publications by an authorized administrator of DigitalCommons@URI. For more information, please contact digitalcommons-group@uri.edu. 


\section{Authors}

Haowen Zheng, Minggang Cai, Wenlu Zhao, Mohammed Khairy, Mian Chen, Hengxiang Deng, and Rainer Lohmann

This article is available at DigitalCommons@URI: https://digitalcommons.uri.edu/gsofacpubs/765 
1 Net volatilization of PAHs from the North Pacific to the Arctic Ocean observed

3 Haowen Zheng ${ }^{\text {a, b}}$; Minggang Cai ${ }^{\text {a, b}}$; Wenlu Zhao ${ }^{\text {c; }}$ Mohammed Khairy ${ }^{\text {d, e}}$; Mian Chen ${ }^{\text {a, }}$

$4 \quad$ b; Hengxiang Deng ${ }^{\text {a, }}$; ;ainer Lohmann ${ }^{\text {d, * }}$

5 a State Key Laboratory of Marine Environmental Science, Xiamen University, Xiamen 361102, China

$6 \quad{ }^{\mathrm{b}}$ College of Ocean and Earth Science, Xiamen University, Xiamen 361102, China

$7 \quad \mathrm{c}$ School of Environmental Science and Engineering, Zhejiang Gongshang University, Hangzhou 310018 ,

8 China

$9{ }^{\mathrm{d}}$ Graduate School of Oceanography, University of Rhode Island, Narragansett, Rhode Island 02882-

10 1197, United States

11 e Department of Environmental Sciences, Faculty of Science, Alexandria University, 21511 Moharam

12 Bek, Alexandria, Egypt

13

$14 *$ Corresponding author: Rainer Lohmann

15 E-mail: rlohmann@uri.edu 
Abstract

The North Pacific-Arctic Oceans are important compartments for semi-volatile organic compounds' (SVOCs) global marine inventory, but whether they act as a "source-sink" remains

19 controversial. To study the air-sea exchange and fate of SVOCs during their poleward long20 range transport, low-altitude atmosphere and surface seawater were measured for polycyclic aromatic hydrocarbons (PAHs) by passive sampling from July to September in 2014. Gaseous PAH concentrations $\left(0.67-13 \mathrm{ng} \mathrm{m}^{-3}\right)$ were dominated by phenanthrene (Phe) and fluorene (Flu),

23 which displayed an inverse correlation with latitude, as well as a significant linear relationship 24 with partial pressure and inverse temperature. Concentrations of PAHs in seawater (1.8-16 ng $\mathrm{L}^{-1}$ ) showed regional characteristics, with higher levels near the East Asia and lower values in the Bering Strait. The potential impact from the East Asian monsoon was suggested for gaseous PAHs, which - similar to PAHs in surface seawater - were derived from combustion sources.

28 In addition, the data implied net volatilization of PAHs from seawater into the air along the 29 entire cruise; fluxes displayed a similar pattern to regional and monthly distribution of PAHs in seawater. Our results further emphasized that air-sea exchange is an important process for PAHs

31 in the open marine environments.

\section{Keywords}

Polycyclic aromatic hydrocarbons; Low-density polyethylene; Air-sea exchange; Long34 range transport; High-latitude marine environment. 


\section{Introduction}

Polycyclic aromatic hydrocarbons (PAHs) are ubiquitous in the environments worldwide, and some of them are toxic, carcinogenic and mutagenic (Bozlaker et al., 2008; Okona-Mensah et al., 2005; Perera et al., 2005). Besides their petrogenic origin, PAHs are also generated during the incomplete combustion of organic materials, like fossil fuels and biomass (Yunker et al., 2002). As a class of semi-volatile organic compounds (SVOCs), they could arrive in the polar area from temperate regions with subsequent deposition and re-volatilization, representing an emerging concern in the Arctic like other conventional pollutants (Cai et al., 2016; Friedman and Selin, 2012; Laender et al., 2011).

Atmospheric transport has been considered the primary pathway for PAHs transported from the lower latitudes to the Arctic environments (Mulder et al., 2015; Dotel et al., 2020). Previous studies showed that PAHs found in the Arctic seawater and sediments mainly originated from natural underwater hydrocarbon seeps, while those in the air were from atmospherically derived sources (Harvey et al., 2014; Yunker et al., 2011; Foster et al., 2015). With the concern of climate change, the "polar sinks" for many conventional pollutants may become secondary sources via air-water exchange, that is, the declining sea ice coverage and rising temperature could lead to an accelerating release of PAHs from sea ice and seawater to the atmosphere (Hung et al., 2010; Ma et al., 2011, 2013; Galban-Malagon et al., 2013). Thus, studying PAHs in the atmosphere and related interfaces is helpful to better know the current state of the PAH emission and their fates in the Arctic (Friedman et al., 2014).

Passive sampling is an effective monitoring technique for SVOCs, which is easy to operate, cost-effective and with high enrichment of the target compounds, and has been applied in various global monitoring projects (Lohmann et al., 2001; Harner et al., 2003; Meijer et al., 2003; Jaward et al., 2004; Khairy and Lohmann, 2014; Mcdonough et al., 2014; Zhao et al., 2018). This method integrates contaminant concentrations over time, representing timeweighted averages (Stuer-Lauridsen, 2005; Shaw and Mueller, 2009; Wania and Shunthirasingham, 2020). For PAHs, the freely-dissolved pollutants can be sampled with lowdensity polyethylenes (LDPEs) (Khairy and Lohmann, 2014). Concentrations of target compounds that do not reach equilibrium during the exposure period can be estimated relying 
on the diffusive loss of performance reference compounds (PRCs) (Booij et al., 2002; Mayer et al., 2003; Khairy and Lohmann, 2012).

Although previous studies have reported the distribution and direction of PAHs air-water exchange in the northern Pacific and the Arctic, as well as fugacity model simulations, the seasonal and regional trends of PAHs remain uncertain (Ke et al., 2017; Ma et al., 2013). Hence the air-sea exchange process of PAHs from the North Pacific to the Arctic needs further research. In this study, we performed spatially resolved air and water measurements during the sampling cruise, and the objectives were to (1) obtain the spatial and temporal distribution characteristics of atmospheric and dissolved PAHs in seawater from the North Pacific Ocean to the western Arctic Ocean; (2) assess the source of gaseous and freely dissolved PAHs at most sites; (3) derive the direction and magnitude of the air-sea flux exchange process of PAHs.

\section{Materials and methods}

\subsection{Area description}

During the Chinese sixth Arctic scientific expedition cruise from July to September in 2014, we collected 32 atmosphere and 16 surface seawater samples in the Japan Sea, Bering Sea and Chukchi Sea onboard the R/V Xuelong (Snow Dragon). The Bering Strait, connecting the Bering Sea with the Chukchi Sea, and linking the Asian and American continents, is the boundary of the Arctic and Pacific Oceans. The Bering Sea is a semi-enclosed, high-latitude sea that is almost divided equally between a deep basin (maximum depth $3500 \mathrm{~m}$ ) and the continental shelves $(<200 \mathrm{~m})$. The eastern broad $(>500 \mathrm{~km})$ shelf of the Bering Sea contrasts with the narrow $(<100 \mathrm{~km})$ western shelf (Stabeno and Van Meurs, 1999). Water in the vast ( $\sim 500 \mathrm{~km}$ wide from east to west and $\sim 800 \mathrm{~km}$ long from north to south) and shallow ( $\sim 50 \mathrm{~m})$ Chukchi Sea (Arctic Ocean) is strongly forced by Pacific Ocean water entering through the Bering Strait (Woodgate et al., 2005), which delivers heat, freshwater, nutrients, and carbon to the Chukchi shelf and the Arctic Ocean.

In this study, there were 16 sampling stations (Table S1 in Supporting Information, SI), of which PS-01 to PS-07 were located in the Sea of Japan and northwest Pacific Ocean, while PS08 to PS-10 in the Bering Sea and the Bering Straits, and PS-11 to PS-16 in the Arctic Ocean (mainly in Chukchi Sea). 


\subsection{Materials Preparation and Field sampling}

\subsubsection{Preparation for LDPEs}

Both atmospheric and seawater samplers were made of LDPEs with PRCs, which is similar to the material used in semipermeable membrane devices; The inclusion of PRCs provided a means to identify the absorption of hydrophobic PAHs by estimating dissipation rates of PRCs (Booij et al., 2002; Lei et al., 2020). LDPEs (10 cm $\times 40 \mathrm{~cm}$ size, $50 \mu \mathrm{m}$ thickness) were cleaned in dichloromethane and n-hexane for $24 \mathrm{~h}$ respectively. Deuterated PAHs (pyrene$\mathrm{d}_{10}$ and benzo [a] pyrene- $\mathrm{d}_{12}$, namely Pyr- $\mathrm{d}_{10}$ and $\mathrm{BaP}-\mathrm{d}_{12}$ ) were used as PRCs to infer the equilibrium concentration of compounds in the passive samplers as in previous work (Booij et al., 2002; Mcdonough et al., 2014). LDPEs were soaked in PRCs and continuously shaken for one month to achieve homogenous uptake prior to deployments.

\subsubsection{Simultaneous sampling in atmosphere and surface seawater}

Atmospheric and surface-seawater LDPEs were deployed and collected simultaneously on the underway R/V Xuelong in the Japan, Bering and Chukchi Seas (Fig. S1), and LDPEs were changed every three days. The sampling site coordinates were calculated as the middle position of the start and end of sampling positions.

Surface-seawater LDPEs were put into a stainless-steel pipe, and continuously exposed to fresh marine surface seawater from the onboard seawater supply. We controlled the flow rate of the seawater such that the LDPEs were submerged constantly. The atmospheric sampling device was installed on the top deck, which was about $26 \mathrm{~m}$ above sea level. The device consisted of two stainless-steel bowls, connected in the middle by a stainless-steel center shaft. The LDPEs, thread on a metal wire, were fastened on the center shaft for sampling. All the LDPE samples were sealed with an aluminum foil bag and stored at $-20^{\circ} \mathrm{C}$.

\subsubsection{Other auxiliary parameters}

Auxiliary parameters such as temperature and salinity were provided by the Xuelong ship real-time monitoring system, and other parameters such as wind speed, wind direction and air temperature were provided by the automatic weather station on board Xuelong ship.

\subsection{Pretreatment and analysis}

LDPE samples were thawed out at room temperature, then cleaned with Milli-Q water and 
any excess water or biofouling was removed with KimWipes. $200 \mathrm{~mL}$ of $\mathrm{n}$-hexane was added to completely cover LDPEs after addition of $50 \mu \mathrm{L} 100 \mathrm{ppb}$ PAHs recovery indicator surrogates (acenaphthalene- $d_{10}$, phenanthrene- $d_{10}$, chrysene- $d_{12}$ and perylene- $d_{12}$, namely Acp- $d_{10}$, Phe- $d_{10}$, Chry- $d_{12}$ and Pery- $d_{12}$ respectively). After extraction for $24 h$, the n-hexane was decanted and the extract was kept in a clean glass bottle. After a solvent exchange to dichloromethane, and repeating the above steps, extracts were combined. The extract was concentrated to $1 \mathrm{~mL}$ in a $30^{\circ} \mathrm{C}$ water bath by a fully automatic sample concentrator, transferred to a volumetric tube and slowly purged to $100 \mu \mathrm{L}$ with high-purity nitrogen. Then $50 \mathrm{ng}$ of deuterated terphenyl and 35 ng of 2, 4, 6-Tribromobiphenyl were added as internal standards. The extract was sealed and frozen for storage before analysis. The weight of the extracted LDPE samples was recorded before and after treatment.

An Agilent 6890-5973 GC-MS equipped with a DB5-MS quartz capillary column (30 m $\times 0.25 \mathrm{~mm}$ i.d. $\times 0.25 \mu \mathrm{m}, \mathrm{J} \& W$ Scientific Inc., Folsom, U.S.A.) was used to detect PAHs. The high purity helium was used as carrier gas with the flow rate of $1 \mathrm{~mL} \mathrm{~min}^{-1}$. The temperature programming of chromatography column started at $90{ }^{\circ} \mathrm{C}$ with three 3 minutes hold, then reached $110{ }^{\circ} \mathrm{C}$ at $5{ }^{\circ} \mathrm{C} \min ^{-1}$ (holding 2 minutes), increased by $8{ }^{\circ} \mathrm{C} \min ^{-1}$ until $200{ }^{\circ} \mathrm{C}$ (holding 3 minutes), and finally reached $315{ }^{\circ} \mathrm{C}$ at $5{ }^{\circ} \mathrm{C} \mathrm{min}-1$ fiv, keeping the final temperature for 5 minutes.

\subsection{Quality assurance and quality control}

Avoiding contamination was an important consideration in all steps associated with the extraction and analysis of LDPEs. All glassware used during pretreatment were cleaned, baked at $450^{\circ} \mathrm{C}$ for at least 4 hours, and thoroughly solvent-rinsed before use. The field blanks were regularly included in the sampling protocol, and included when samplers were changed during deployment and retrieval. Method detection limits (MDLs) were calculated as three times the standard deviation of the average field blank concentration. The MDL of the target compounds are listed in SI as well as instrument detection limits. All of the data were blank-corrected. When the concentration of the target compounds was less than the detection of limits, half of MDL was taken as its concentration value (Antweiler and Taylor, 2008).

22 PAHs were detected in this study. In addition to the 16 priority PAHs listed by U.S. 
153 Due to the high environmental background concentration of naphthalene, it will not be 154 discussed in this study. In order to improve the quality and credibility of the data, if the concentration of a certain target compound was greater than MDL but detected at less than $20 \%$ of the total sites, it was omitted from the discussion. A total of nine PAHs in atmospheric samples were regularly detected, which included phenanthrene (Phe), fluorene (Flu), Phe, anthracene (Ant), 1-MePhe, fluoranthene (FluA), pyrene (Pyr), chrysene (Chry), benzo[b]fluoranthene $(\mathrm{BbF}) /$ benzo[k]fluoranthene $(\mathrm{BkF})$ (because the peaks of $\mathrm{BbF}$ and $\mathrm{BkF}$ were hard to chromatographically separate, the total concentration of $\mathrm{BbF} / \mathrm{BkF}$ are reported). While 11 PAHs in surface seawater samples were effectively detected, which included Flu, Phe, Ant, 1-MePhe, FluA, Pyr, Chry, Biph, benz[a]anthracene (BaA), BbF/BkF. Concentrations of PAHs in the samples were blank-corrected for the amounts detected in the field blanks, but not recovery corrected. The average recovery rates of the four surrogates that Acp- $\mathrm{d}_{10}$, Phe- $\mathrm{d}_{10}$, Chry- $\mathrm{d}_{12}$, and Pery- $\mathrm{d}_{12}$ were $70 \pm 12,75 \pm 15,85 \pm 13$, and $74 \pm 18 \%$ respectively.

For the uncertainty analysis, it is difficult to estimate the overall uncertainty of air-water exchange by passive sampling, because it involves multiple mathematical functions and values that have both normal and lognormal errors associated with them. Additionally, the uncertainties in $\mathrm{H}^{\theta}$ are not well characterized, causing the uncertainty associated with the temperature- and salinity corrections were not included.

\subsection{Calculations and data analysis}

\subsubsection{Calculations of PAH concentrations}

For each compound, the fraction of equilibrium (f) achieved for each compound was determined by fitting the equilibrium of the PRCs using temperature-corrected air-water partitioning coefficient in LDPEs ( $\left.\mathrm{K}_{\mathrm{PE}}\right)$ values to a model curve derived from equation (1) (Liu et al., 2016),

$$
f=1-e^{-\frac{R_{S} t}{K_{P E} M_{P E}}}
$$

Where $R_{s}\left(L\right.$ day $\left.^{-1}\right)$ is the sampling rate defined as the volume of water or air that comes into contact with the sampler per day; $\mathrm{t}$ is deployment time (days); $\mathrm{M}_{\mathrm{PE}}$ is the PE weight (kg); 
the values of $R_{s}$ can be estimated using nonlinear least squares methods, by considering $f$ as a continuous function of $K_{P E}$, with $R_{s}$ as an adjustable parameter using Excel Solver to obtain the best fit (Booij and Smedes, 2010). The average gaseous sampling rate of PAHs was $1700 \pm 1$ $500 \mathrm{~m}^{3}$ day $^{-1}$, among which the Pacific Ocean and the Bering Sea was $620 \pm 410 \mathrm{~m}^{3}$ day $^{-1}$, however the Arctic Ocean was $3100 \pm 1300 \mathrm{~m}^{3}$ day $^{-1}$, resulted from different wind speed and directions described below. The aqueous sampling rate of PAHs was $140 \pm 54 \mathrm{~L} \mathrm{day}^{-1}$.

Gaseous and freely dissolved concentrations, $\mathrm{C}_{\mathrm{A} / \mathrm{w}}$ of compounds were calculated from the equation (2),

$$
C_{A / W}=\frac{C_{P E}-C_{\text {Blank }}}{K_{P E}\left(1-e^{-\frac{R_{S} t}{K_{P E} M_{P E}}}\right)}
$$

Where $\mathrm{C}_{\mathrm{PE}}$ is the PE-normalized concentrations. For more details, see the Supporting Information.

\subsubsection{Brief description of calculation and two-film model}

The Whitman two-film resistance model was used for the air-sea exchange flux $\left(\mathrm{F}_{\mathrm{aw}}\right)$ calculation in the modified version (Liss and Slater, 1974).

$$
\mathrm{F}_{\mathrm{a} / \mathrm{w}}=\mathrm{v}_{\mathrm{a} / \mathrm{w}}\left(\mathrm{C}_{\mathrm{w}}-\frac{C_{\mathrm{a}}}{K_{\mathrm{a} w}}\right)
$$

where $\mathrm{F}_{\mathrm{a} / \mathrm{w}}$ is calculated with the mass transfer velocity $\left(\mathrm{v}_{\mathrm{a} / \mathrm{w}}\right)$, the concentrations in seawater and atmosphere, $\mathrm{C}_{\mathrm{w}}$ and $\mathrm{C}_{\mathrm{a}}$, and air-water partitioning coefficient corrected by ambient temperature, $\mathrm{K}_{\mathrm{aw}}$ (Liu et al., 2016). Calculation details of PAHs air-sea exchange fluxes at different sites are listed in SI from Table S6 to S12.

\subsection{Air mass back trajectories}

The NOAA's HYSPLIT model was used to track the origins of air masses (Draxler and Hess, 1998). Air mass back trajectories were set as $12 \mathrm{~h}$ steps that traced back the air masses for 5 days, using the sampling height as arrival height. 


\section{Results and discussion}

\subsection{PAHs in the atmosphere}

\subsubsection{Concentrations and distributions}

Total gaseous concentrations of $\sum_{9} \mathrm{PAH}$ ranged from 0.67 to $13 \mathrm{ng} \mathrm{m}^{-3}$ with the mean value of 3.7 $\pm 3.0 \mathrm{ng} \mathrm{m}^{-3}$, close to previous data of $0.93-93 \mathrm{ng} \mathrm{m}^{-3}$ for $\Sigma_{15} \mathrm{PAH}$ reported over the North Pacific and Arctic Ocean in 2003, as well as $0.91-7.4 \mathrm{ng} \mathrm{m}^{-3}$ with a mean of $3.3 \pm 1.7 \mathrm{ng} \mathrm{m}^{-3}$ for $\Sigma_{18}$ PAH reported in 2010 (Ding et al., 2007, Ma et al., 2013). Observation showed the maximum concentrations occurred at PS-01 located in the Bohai Sea, and lowest at PS-16 in the Arctic Ocean (Fig. 1, Table S3).

In this study, nine different PAHs were regularly detected in most gaseous samples, including three-ring PAHs like Flu, Phe, 1-MePhe, Ant, and four-ring PAHs like FluA, Pyr, and Chry. Higher molecular weight PAH concentrations in the atmosphere were typically below their limits of detection. Across the entire sampling cruise, Phe displayed the highest average contribution of $52 \%$ to $\sum{ }_{9} \mathrm{PAH}$, followed by Flu, which contributed another $44 \%$. Hence, the cumulative contributions of other congeners were less than $5 \%$. Our results mirror previous results, in that Phe was also the dominant compound among the gas phase PAHs, contributing $50 \%$ to $\Sigma_{15}$ PAH over the North Pacific and Arctic Ocean (Ding et al., 2007).

\subsubsection{Decreasing distribution with latitude}

Overall, a significant negative correlation was observed between gaseous $\sum_{9} \mathrm{PAH}$ and latitude (the coefficients of determination, $\mathrm{R}^{2}$ was 0.61 , the P-value $<0.0010$ ). The partial pressure of seven PAH congeners were calculated by a modified Clausius-Clapeyron equation (Venier et al., 2012), these results were obviously consistent with the trends in concentration with temperature. The mobility of PAHs was usually reduced by decreasing temperature, which contributed to decreasing volatility of PAHs, especially for higher molecular weight PAHs. As shown in Fig. 2, the partial pressure of FluA, Pyr and Chry decreased faster than for the low molecular weight PAHs such as Flu and Phe (All the $\mathrm{R}^{2}$ and P-values are given in SI). Higher molecular weight PAH congeners were more sensitive to temperature change, in line with expectations for gaseous PAH concentrations with latitude (Fig. 2).

On the other hand, PAHs are more susceptible to photochemical-degradation in the 
233 atmosphere. The concentration ratios of Flu to Phe were positively related to latitude $\left(\mathrm{R}^{2}=0.58\right.$,

$234 \mathrm{P}<0.0010$ ) from the North Pacific to the Arctic (Figure 1); and the ratio FluA/(FluA+Pyr) was 235 greater than 0.5 at all stations (Fig. 4). The total photochemical residence time ( $\left.\tau_{\text {total }}\right)$ of Flu and 236 FluA were derived as 21 and 20 hours, and 9 and 5 hours for Phe and Pyr, respectively (Keyte 237 et al., 2014); the observed low concentrations of Ant in the atmosphere were likely caused by 238 its 2 hours of $\tau_{\text {total }}$. Furthermore, the atmospheric half-life of Flu is higher than Phe, which 239 means higher removal rates occurred in Phe, and Flu presents a greater transmission potential 240 than Phe for long-range atmospheric transport (LRAT) (Halsall et al., 2001).

\section{$241 \quad$ 3.1.3 Influence of air mass}

242 Diagnostic ratios of gaseous PAHs were calculated, but need to be interpreted with caution, 243 because the ratios might be affected by potential post emission processes. 1-MePhe/Phe in the 244 atmosphere were less than 0.50, implying that the source of the PAHs could be attributed to 245 combustion processes (Yunker et al., 2002; Deka et al, 2016; Wu et al., 2019). This was further 246 supported by the isomeric ratios of FluA/(FluA+Pyr) that ranged from $0.42-0.82$; a ratio greater 247 than 0.5 indicates the main sources of grass, wood or coal combustions, and between 0.4 to 0.5 248 usually suggests petrogenic combustion (Qu et al., 2019; Qi et al., 2020).

249 At the mid-latitude sites, the air mass mainly originated from the coast of China, Korea, 250 Japan and Russia, and close-by terrestrial regions as indicated by the air mass back trajectories 251 (Fig. S7 and S8 in SI). With the trajectories of air mass that was used to study the origin of 252 atmospheric PAHs in Japan and other neighboring areas, high concentrations of PAHs and 253 emissions have been already observed in East Asian areas (Ohura et al., 2004; Primbs et al., 254 2007). Continuously decreasing concentrations of PAHs occurred from the Bering Sea to the 255 Arctic, but increased again between PS-09 and PS-11, where back trajectories indicated the air 256 had passed through Alaska and Siberia, especially on Kamchatka peninsula, consistent with the 257 impact of terrestrial source (Fig. S8 in SI). According to the air mass back trajectories, the 258 source of the atmosphere PAHs in July was significantly affected by the southwest monsoon, 259 which is also an important pathway for long-range transport. 


\subsubsection{PAH profiles in seawater}

The concentrations of total freely dissolved $\sum_{11} \mathrm{PAH}$ in the surface seawater ranged from 1.8 to $16 \mathrm{ng} \mathrm{L}^{-1}$ with the mean value of $7.7 \pm 4.6 \mathrm{ng} \mathrm{L}^{-1}$. The maximum concentrations occurred 264 at PS-03 on the northeast coast of Japan, followed by station PS-02 and PS-04, and the 265 minimum was observed at PS-10 in the Bering Strait (Fig. 3, Table S4). A total of 11 different 266 PAHs were regularly detected in the freely-dissolved phase in the seawater samples, including 267 Biph, Flu, Phe, 1-MePhe, Ant, FluA, Pyr, and Chry, BaA, BbF/BkF. The concentrations of higher molecular weight PAHs in seawater were typically below the limits of detection, similar to the atmosphere.

The ratios of $1-\mathrm{MePhe} / \mathrm{Phe}$ and $\mathrm{FluA} /(\mathrm{FluA}+\mathrm{Pyr})$ indicated the main sources of combustions included many types (Yunker et al., 2002; Qu et al., 2019; Qi et al., 2020). The results in seawater were consistent to previous studies in the North Pacific and Arctic Ocean (Ding et al., 2007; Ma et al., 2013).

While Phe also dominated the dissolved $\sum_{11} \mathrm{PAH}$, its average contribution was only $36 \%$. Hence more PAHs were regularly present beyond Phe, including Flu, which contributed 25\%, FluA (11\%), Pyr (10\%), in addition 1-MePhe and Biph were $8 \%$ and $5 \%$, respectively. Other congeners like Ant, $\mathrm{BaA}, \mathrm{BbF} / \mathrm{BkF}$ were only detected in a few of the samples beyond the

278 Bering Sea (for details see SI), whose contributions were less than $4 \%$. The combined 279 influences of sources like rivers, runoff, currents as well as biogeochemical process cause more 280 higher molecular weight PAHs to be present in the surface seawater (Sambrotto, 1984; 281 McDonough et al., 2014). We speculate that differences in biodegradation and photochemical282 degradation of PAHs increased the proportion of higher molecular weight PAHs in seawater 283 (González-Gaya et al., 2019). Bacterial degradation rate constants $\left(\mathrm{K}_{\mathrm{D}}\right)$ showed a significant 284 inverse correlation with $\mathrm{K}_{\mathrm{ow}}$, which means the capacity to biodegrade higher molecular weight 285 and hydrophobic PAHs (i.e., FluA, Pyr, Chry, BbF/BkF) were slower than for lighter weight 286 PAHs (Table S5) (Tucca et al., 2020). Besides, higher molecular weight PAHs in the air sorb to 287 aerosol according their higher octanol-air ratios, contributing to wet and dry deposition entering seawater. 


\subsubsection{Changes of freely-dissolved PAH distribution with region}

Freely dissolved $\sum_{11} \mathrm{PAH}$ concentrations varied with sampling locations as well, but displayed obvious regional trends instead of correlation with latitude. They ranged from 12 to $16 \mathrm{ng} \mathrm{L}^{-1}$ in the Japan Sea to the North Pacific Ocean, located in a mid-latitude temperate zone.

293 Concentration were lower in the nearby Bering Strait ranging only from 1.8 to $4.8 \mathrm{ng} \mathrm{L}^{-1}$, as 294 well as sites in the Arctic Ocean (2.7-6.5 $\left.\mathrm{ng} \mathrm{L}^{-1}\right)$. In general, dissolved $\sum_{11} \mathrm{PAH}$ concentrations closer to shore were relatively higher than those in the open ocean (Fig. 3).

Lower concentrations of seawater $\Sigma_{11}$ PAH were present at station PS-08, PS-09 and PS10 in the Bering Strait, which was known as one of the most productive waters in the Arctic Ocean. Likely removal of PAHs by high amounts of biogenic particles significantly decreased the concentration of PAHs in the ocean, where the plankton biomass was higher, consistent with the relevance of the biological pump (González-Gaya et al., 2019). Another reason for low concentrations of $\Sigma_{11} \mathrm{PAH}$ in the Arctic Ocean are the oceans' long residence time, as well as the weak sea ice melting in summer. The ocean current exchange is relatively slow, causing the residence time of surface water to be about 10 years. Melting sea ice has been recognized as an important factor controlling the distribution of PAHs in the Arctic, where only part of the sea ice melts even in summer (MacDonald et al., 2000). The lower salinity supported that continental runoff or melting ice rather than ocean currents were the pathways of PAHs into the surface water, and the atmospheric deposition was also a key source (see below).

\subsection{Air-sea exchange of PAHs with two-film model}

\subsubsection{General net volatilization}

The air-sea exchange fluxes of the seven PAHs was generally dominated by net

312 fluxes of the more volatile PAHs especially for Flu and Phe were greater and nearly accounted 313 for $>70 \%$ of all (Table S12 in SI), based on their dominant contribution to gaseous and free314 dissolved PAHs. The maximum values of volatilization and deposition fluxes of $\Sigma_{9}$ PAHs were 315 observed at site PS-04 $\left(11 \mu \mathrm{g} \mathrm{m}^{-2}\right.$ day $\left.^{-1}\right)$ and PS-01 $\left(-2.5 \mu \mathrm{g} \mathrm{m}^{-2}\right.$ day $\left.^{-1}\right)$ respectively. Flux 316 distributions indicated that the deposition was only observed near land from Shanghai to the 317 Bohai Sea, while net volatilizations were more widespread. For instance, Flu dominated the 
318 flux at site PS-04 with the value of $4.2 \mu \mathrm{g} \mathrm{m}^{-2}$ day $^{-1}$, and Phe at site PS-01 was $-5.2 \mu \mathrm{g} \mathrm{m}^{-2}$ day $^{-}$

319 , due to the greatest concentrations of dissolved Flu at PS-04 and gaseous Phe at PS-01 320 respectively. The effect of volatilization from coastal waters with high PAH levels has reported 321 in other PAH-impacted regions such as the Atlantic, Narragansett Bay (USA) and the southeast 322 Mediterranean (Nizzetto et al., 2008; Castro-Jiménez et al., 2012; Lohmann et al., 2011). The 323 fluxes were mainly contributed by three-ring PAHs, while the fluxes of four-ring PAHs showed 324 less variation in the North Pacific and the Arctic.

$325 \quad$ 3.3.2 Flux trend closely coupling with dissolved phase

326 The derived air-water exchange fluxes correlated significantly to regional and monthly 327 changes, similar to the freely-dissolved PAH distributions, which might imply the one of driver 328 by concentration gradients between seawater and air (Fig. 5). Volatilizations dominated in the air-sea exchange because the seawater concentrations corrected by $\mathrm{K}_{\mathrm{aw}}$ were one to three orders of magnitudes higher than equivalent concentrations in the atmosphere.

As for individual congeners, there were no clear trends for three-ring PAHs, but diverse ones for higher-ring PAHs, especially FluA and Pyr declined with increasing latitude (Fig. S5 in SI). These results verified that higher molecular weight PAHs were more sensitive to changes

334 with temperature. PAHs are moderately volatile and hydrophobic, which facilitates their partitioning from air and water into organic phases (Nizzetto et al., 2010). Obvious outputs of

336 biogenic particles occurred in the Bering Strait and caused a significant decrease in seawater 337 concentration as well as fluxes. In the Arctic, low PAHs fluxes were driven basically by low atmospheric and seawater concentrations. However, the net volatilizations only had a minor impact on atmospheric concentration. According to the long-range transport and diffusion advection of PAHs, the atmospheric concentrations tend to decrease as the latitude increases, so the transports depend largely on temperature changes. In our study, strong correlations were observed for air-sea exchange fluxes with concentrations rather than temperature.

\section{$343 \quad 3.4$ Implication for the source-sink pattern of PAHs}

\section{$344 \quad$ 3.4.1 Source pattern of PAHs from the Pacific to the Arctic}

For further analysis, principal component analysis (PCA) was used to elucidate linear combinations of PAHs, to distinguish between the samples to assess different sources (Nemr et 
347 al., 2005). Two compounds were obtained from PCA, namely the first principal component 348 (PC1) and second principal component (PC2), contributed $74 \%$ to the total variance (Fig. 4).

349 Correlation analysis showed high relevance of PC1 for four-ring PAHs, such as FluA and Pyr 350 ( $\mathrm{r}=0.98)$, FluA and Chry $(\mathrm{r}=0.90)$, Pyr and Chry $(\mathrm{r}=0.94)$; and PC2 represented mainly three351 ring PAHs such as Flu and Phe (r=0.82), Flu and Ant ( $\mathrm{r}=0.56)$, Phe and 1-MPhe ( $\mathrm{r}=0.67)$. The 352 scores on PCA showed that all the sites in the Bering Sea and Arctic were concentrated together 353 in the negative axis of PC1 and PC2, while sites in the North Pacific were more dispersed.

354 The diagnostic ratios and PCA analysis provided qualitative information about the spatial patterns of PAH sources. Based on the analysis mentioned earlier, we inferred that sources of seawater and atmospheric PAHs in the Bering Sea and Arctic were mainly from combustion processes. In the Arctic, the diagnostic ratios of PAH concentrations in seawater were similar

358 to that in atmosphere, which might provide the evidence that PAHs reached high latitudes by 359 long-range atmosphere transport (LRAT). Hence the atmospheric concentrations contributed 360 only low levels in the high latitudes, and combined with sea ice melting, runoff and other 361 biogeochemical process to affect the ratio characteristics. On the other hand, both of the 362 seawater and atmospheric PAHs in the Pacific Ocean were also mainly derived from 363 combustion processes. The difference is that the North Pacific is known as an important cruise 364 routes area, which potentially contributes additional sources factors, complicating the seawater 365 PAHs. Therefore, petroleum combustion emitted by ships is an inevitable source for PAHs in 366 addition to runoff, ocean currents and atmospheric deposition.

\section{$367 \quad 3.4 .2$ Net volatilization prospect under climate changing}

368 Our results illustrated that the majority of PAHs displayed a net volatilization trend from 369 East Asia to the Arctic, which was on the contrary of the previous studies (Zhong et al., 2012; 370 Ma et al., 2013). The significant differences in the fluxes were partly attributed to the different 371 concentrations of gaseous and dissolved PAHs between these two studies whose samples were 372 from different years. The time lag to previous studies might have been sufficient to cause an 373 increase in PAH concentration in surface seawater for the ongoing-emitted PAHs year by year.

374 In addition, East Asia is a possible continental source area and has been estimated to contribute 375 greatly to the global emission inventory of PAHs (Shen et al., 2013). Furthermore, sea surface 376 temperatures (SSTs) in August 2014 were as much as $4{ }^{\circ} \mathrm{C}$ warmer than the 1982-2010 August 
mean in the Bering Strait and the sixth smallest Arctic sea ice extent by the satellite record

378 (1979-2014) occurred in the summer of 2014 (Chen et al., 2016), which might partially explain

379 the different results reported here. Lastly, sampling of PAHs by passive sampling only captures

380 freely dissolved or gas-phase compounds, which should lead to air-water exchange fluxes not 381 impacted by inadvertent capture of PAH bound to colloids or small particles.

382 Some persistent organic pollutants, whose primary emissions have been reduced, are 383 suggested having iterative processes (including deposition, volatilization and re-deposition) in 384 the changing Arctic (Cai et al., 2012). Since the ice will prevent the escape of PAHs in winter, we can assume that atmospheric PAHs will deposit in snow and ice by dry/wet deposition

386 processes and the Arctic turned into a sink again. In other words, as a result of global warming 387 with sea ice retreat, whether the polar region is a sink or secondary source depends on the 388 seasonal variety. The air-sea exchange fluxes in our study displayed significantly lower in 389 September than in July (Fig. 5), which might be driven by decreasing temperature and 390 weakened monsoon. PAH concentrations and fluxes are thus likely affected by temporal 391 changes, but more evidence is needed (Fig. S6 in SI). Combining this with our result that fluxes 392 were consistent with surface seawater PAHs concentrations, then seawater might dominate the 393 air-sea exchange when not covered by sea ice. But whether the hypothesis is reasonable or not 394 need to be further studied, and which might determine the role of the Arctic as "sink" or "source" 395 of PAHs.

\section{Conclusions}

This study focused on the air-sea exchange process of PAHs, relying on LDPEs passive 398 sampling from the North Pacific to Arctic. The gaseous concentrations of $\sum_{9} \mathrm{PAH}$ ranged from 3990.67 to $13 \mathrm{ng} \mathrm{m}^{-3}$ and displayed a significant decreasing trend with latitude, which was 400 dominated by long-range transport and photochemical-degradation of PAHs. Different 401 distributions were explained by the air mass back trajectories, coupled with the influence of air402 sea exchange and dry/wet deposition processes. The concentrations of total freely dissolved $403 \quad \sum_{11} \mathrm{PAH}$ ranged from 1.8 to $16 \mathrm{ng} \mathrm{L}^{-1}$ whereas higher molecular weight PAHs showed more 404 presence. The changes in PAH profiles can likely be attributed to their relative capacity to 405 undergo biodegradation and dry/wet deposition. In addition, regional distributions were shown 
406 in freely dissolved PAHs, showing high levels in the North Pacific. The lower levels were

407 impacted by biogenic particle removals in the Bering Sea, and were attributed to slow renewal

408 of seawater and melting ice in the Arctic. Molecular ratios of the PAHs in atmosphere and

409 surface seawater indicated combustion sources, and the source indication might provide some

410 evidence for LRAT of high-latitude marine environmental PAHs. Overall, the air-sea fluxes of

411 PAHs presented mostly net volatilizations with special regional and monthly changes,

412 controlled by seawater concentrations. The air-sea exchange process showed only a relatively

413 minor importance of air concentrations, instead the fluxes and dry/wet depositions from

414 atmosphere to seawater might were more important especially in the Arctic.

415 Acknowledgements

416 We thank all the members of the sixth Chinese National Arctic Research Expedition 417 onboard the R/V Xuelong (Snow Dragon) in 2014. This study was supported by the National 418 Natural Science Foundation of China (NSFC) (U2005207, 41976216). We thank Mengyang 419 Liu for helpful discussion and guide of figures, Chunhui Wang and Jun Ye for lab management. 


\section{Reference}

Antweiler, R. C., Taylor, H. E., 2008. Evaluation of statistical treatments of left-censored environmental data using coincident uncensored data sets: I. Summary statistics. Environmental Science \& Technology, 42(10): 3 732-3 738.

Booij, K., Smedes, F., 2010. An improved method for estimating in situ sampling rates of nonpolar passive samplers. Environmental Science \& Technology, 44(17): 6 789-6 794.

Booij, K., Smedes, F., van Weerlee, E. M., 2002. Spiking of performance reference compounds in low density polyethylene and silicone passive water samplers. Chemosphere, 46(8): 1 157-1 161.

Bozlaker, A., Muezzinoglu, A., Odabasi, M., 2008. Atmospheric concentrations, dry deposition and airsoil exchange of polycyclic aromatic hydrocarbons (PAHs) in an industrial region in Turkey. Journal of Hazardous Materials, 153(3): 1 093-1 102.

Cai, M. G., Liu, M. Y., Hong, Q. Q., Lin, J., Huang, P., Hong, J. J., Wang, J., Zhao, W. L., Chen, M., Cai, M. H., Ye, J., 2016. Fate of polycyclic aromatic hydrocarbons in seawater from the Western Pacific to the Southern Ocean (17.5 degrees ${ }^{\circ} \mathrm{N}$ to 69.2 degrees $\left.{ }^{\circ} \mathrm{S}\right)$ and their inventories on the Antarctic Shelf. Environmental Science \& Technology, 50(17): 9 161-9 168.

Cai, M. H., Ma, Y. X., Xie, Z. Y., Zhong, G. C., Moeller, A., Yang, H. Z., Sturm, R., He, J. F., Ebinghaus, R., Meng X. Z.,. 2012. Distribution and air-sea exchange of organochlorine pesticides in the North Pacific and the Arctic. Journal of Geophysical Research-Atmospheres, 117: D06311.

Castro-Jiménez, J., Eisenreich, S. J., Mariani, G., Skejo, H., Umlauf G., 2012. Monitoring atmospheric levels and deposition of dioxin-like pollutants in sub-alpine Northern Italy. Atmospheric Environment, 56: 194-202.

Chen, H. W., Alley, R. B., Zhang, F., 2016. Interannual Arctic sea ice variability and associated winter weather patterns: A regional perspective for 1979-2014. Journal of Geophysical ResearchAtmospheres, 121(24): 14 433-14 455.

Deka, J., Sarma, K. P., Hoque, R. R., 2016. Source contributions of Polycyclic Aromatic Hydrocarbons in soils around oilfield in the Brahmaputra Valley. Ecotoxicology and Environmental Safety, 133: 281-289.

Ding, X., Wang, X. M., Zhou, Q. X., Cai, H. X., Bi, X. M., Li, G. S., Zheng, M., Guo, Y. S., Jia, M. F., Poeschl, U., 2007. Atmospheric polycyclic aromatic hydrocarbons observed over the North Pacific Ocean and the Arctic area: Spatial distribution and source identification. Atmospheric Environment, 41(10): 2 061-2 072.

Dotel, J., Gong, P., Wang, X. P., Pokhrel, B., Wang, C. F., Nawab, J., 2020. Determination of dry deposition velocity of polycyclic aromatic hydrocarbons under the sub-tropical climate and its implication for regional cycling. Environmental Pollution, 261: 114143.

Draxier, R. R., Hess, G. D., 1998. An overview of the HYSPLIT_4 modelling system for trajectories, dispersion and deposition. Australian Meteorological Magazine, 47(4): 295-308.

Foster, K. L., Stern, G. A., Carrie, J., Bailey, J. N. L., Outridge, P. M., Sanei, H., Macdonald, R. W., 2015. 
Spatial, temporal, and source variations of hydrocarbons in marine sediments from Baffin Bay, Eastern Canadian Arctic. Science of The Total Environment, 506: 430-443.

Friedman, C. L., Selin, N. E., 2012. Long-range atmospheric transport of polycyclic aromatic hydrocarbons: a global 3-D model analysis including evaluation of Arctic sources. Environmental Science \& Technology, 46(17): 9 501-9 510.

Friedman, C. L., Zhang, Y. X., Selin, N. E., 2014. Climate Change and Emissions Impacts on Atmospheric PAH Transport to the Arctic. Environmental Science \& Technology, 48(1): 429437.

Hung, H., Kallenborn, R., Breivik, K., Su, Y. S., Brorström-Lundén, E., Olafsdottir, K., Thorlacius, J. M., Leppänen, S., Bossi, R., Skov, H., Mano, S., Patton, G. W., Stern, G., Sverko, E., Fellin, P., 2010. Atmospheric monitoring of organic pollutants in the Arctic under the Arctic Monitoring and Assessment Programme (AMAP): 1993-2006. Science of the Total Environment, 408(15): 2 854-2 873.

Jaward, F., Farrar, N., Harner, T., Sweetman, A., Jones, K., 2004. Passive air sampling of PCBs, PBDEs, and organochlorine pesticides across Europe. Environmental Science \& Technology, 38(1): 3441.

Ke, H. W., Chen, M., Liu, M. Y., Chen, M., Duan, M. S., Huang, P., Hong, J. J., Lin, Y., Cheng, S. Y., Wang, X. R., Huang, M. X., Cai, M. G., 2017. Fate of polycyclic aromatic hydrocarbons from the North Pacific to the Arctic: Field measurements and fugacity model simulation. Chemosphere, 184: 916-923.

Keyte, I. J., Harrison, R. M., Lammel, G., 2014. Chemical reactivity and long-range transport potential of polycyclic aromatic hydrocarbons: A review. Chemical Society Reviews, 45(24): 9333-9 391.

Khairy, M. A., Lohmann, R., 2012. Field validation of polyethylene passive air samplers for parent and 
alkylated PAHs in Alexandria, Egypt. Environmental Science \& Technology, 46(7): 3 990-3 998.

Khairy, M. A., Lohmann, R., 2014. Field calibration of low density polyethylene passive samplers for gaseous POPs. Environmental Science -Processes \& Impacts, 16(3): 414-421.

Laender, F. D., Hammer, J., Hendriks, A. J., Soetaert, K., Janssen, C. R., 2011. Combining monitoring data and modeling identifies PAHs as emerging contaminants in the Arctic. Environmental Science \& Technology, 45(20): 9 024-9 029.

Lei, P., Zhu, J. J., Pan, K., Zhang, H., 2020. Sorption kinetics of parent and substituted PAHs for lowdensity polyethylene (LDPE): Determining their partition coefficients between LDPE and water (K-LDPE) for passive sampling. Journal of Environmental Sciences, 87: 349-360.

Liss, P. S., Slater, P. G., 1974. Flux of gases across the air-sea interface. Nature, 247: 181-84. Doi: $10.1038 / 247181 \mathrm{a} 0$

Liu, Y., Wang, S. Y., McDonough, C. A., Khairy, M., Muir, D. C. G., Helm, P. A., Lohmann., R., 2016. Gaseous and freely-dissolved PCBs in the lower Great Lakes based on passive sampling: Spatial trends and air-water exchange. Environmental Science \& Technology, 50(10): 4 932-4 939.

Lohmann, R., Corrigan, B. P., Howsam, M., Jones, K. C., Ockenden, W. A., 2001. Further developments in the use of semipermeable membrane devices (SPMDs) as passive air samplers for persistent organic pollutants: Field application in a spatial survey of PCDD/Fs and PAHs. Environmental Science \& Technology, 35(12): 2 576-2 582.

Lohmann, R., Dapsis, M., Morgan, E. J., Dekany, V., Luey, P. J., 2011. Determining air-water exchange, spatial and temporal trends of freely dissolved PAHs in an urban estuary using passive polyethylene samplers. Environmental Science \& Technology, 45(7): 2 655-2 662.

Ma, J. M., Hung, H., Tian, C. G., Kallenborn, R., 2011. Revolatilization of persistent organic pollutants in the Arctic induced by climate change. Nature Climate Change, 1(5): 255-260.

Ma, Y. X., Xie, Z. Y., Yang, H. Z., Möller, A., Halsall, C., Cai, M. H., Sturm, R., Ebinghaus, R., 2013. Deposition of polycyclic aromatic hydrocarbons in the North Pacific and the Arctic. Journal of Geophysical Research Atmospheres, 118(11): 5 822-5 829.

MacDonald, R. W., Barrie, L. A., Bidleman, T. F., Diamond, M. L., Gregor, D. J., Semkin, R. G., Strachan, W. M. J.,. Li, Y. F, Wania, F., Alaee, M., Alexeeva, L. B., Backus, S. M., Bailey, R., Bewers, J. M., Gobeil, C., Halsall, C. J., Harner, T., Hoff, J. T., Jantunen, L. M. M., Lockhart, W. L., Mackay, D., Muir, D. C. G., Pudykiewicz, J., Reimer, K. J., Smith, J. N., Stern, G. A., Schroeder, W. H., Wagemann, R., Yunker, M. B., 2000. Contaminants in the Canadian Arctic: 5 years of progress in understanding sources, occurrence and pathways. Science of the Total Environment, 254(23): 93-234.

Mayer, P., Toll, J., Hermens, L., Mackay, D., 2003. Equilibrium sampling devices. Environmental Science \& Technology, 37(9): 184A-191A.

McDonough, C. A., Khairy, M. A., Muir, D. C. G., Lohmann, R., 2014. Significance of population centers as sources of gaseous and dissolved PAHs in the Lower Great Lakes. Environmental Science \& Technology, 48(14): 7 789-7 797.

Meijer, S. N., Shoeib, M., Jantunen, L. M. M., Jones, K. C., Harner, T., 2003. Air-soil exchange of 
organochlorine pesticides in agricultural soils. 1. Field measurements using a novel in situ sampling device. Environmental Science \& Technology, 37(7): 1 292- 1299.

Mulder, M. D., Angelika H., Kukučka, P., Kuta, J., Přibylová, P., Prokeš, R., Lammel, G., 2015. Longrange atmospheric transport of PAHs, PCBs and PBDEs to the central and eastern Mediterranean and changes of PCB and PBDE congener patterns in summer 2010. Atmospheric Environment, 111: 51-59.

Nemr, A. E., Khaled, A., El-Sikaily, A., Said, T. O., Abd-Allah, A. M. A., 2005. Distribution and sources of polycyclic aromatic hydrocarbons in surface sediments of the Suez Gulf. Environmental Monitoring and Assessment, 111: 333-358.

Nizzetto, L., Lohmann, R., Gioia, R., Jahnke, A., Temme, C., Dachs, J., Herckes, P., Di Guardo, A., Jones K. C., 2008. PAHs in air and seawater along a North-South Atlantic transect: Trends, processes and possible sources. Environmental Science \& Technology, 42(5): 1 580-1 585.

Nizzetto, L., Macleod, M., Borga, K., Cabrerizo, A., Dachs, J., Di Guardo, A., Ghirardello, D., Hansen, K. M., Jarvis, A., Lindroth, A., Ludwig, B., Monteith, D., Perlinger, J. A., Scheringer, M., Schwendenmann, L., Semple, K. T., Wick, L. Y., Zhang, G., Jones, K. C., 2010. Past, present, and future controls on levels of persistent organic pollutants in the global environment. Environmental Science \& Technology, 44(17): 6 526-6 531.

Ohura, T., Amagai, T., Fusaya, M., Matsushita, H., 2004. Spatial distributions and profiles of atmospheric polycyclic aromatic hydrocarbons in two industrial cities in Japan. Environmental Science \& Technology, 38(1): 49-55.

Okona-Mensah, K. B., Battershill, J., Boobis, A., Fielder, R., 2005. An approach to investigating the importance of high potency polycyclic aromatic hydrocarbons (PAHs) in the induction of lung cancer by air pollution. Food and Chemical Toxicology, 43: 1 103-1 116.

Primbs, T., Simonich, S., Schmedding, D., Wilson, G., Jaffe, D., Takami, A., Kato, S., Hatakeyama, S., Kajii, Y., 2007. Atmospheric outflow of anthropogenic semivolatile organic compounds from East Asia in spring 2004. Environmental Science \& Technology, 41(10): 3 551-3 558.

Perera, F., Tang, D. L., Whyatt, R., Lederman, S. A., Jedrychowski, W., 2005. DNA damage from polycyclic aromatic hydrocarbons measured by benzo[a]pyrene-DNA adducts in mothers and newborns from Northern Manhattan, the World Trade Center Area, Poland, and China. Cancer Epidemiology Biomarkers \& Prevention, 14(3): 709-714.

Qi, P. Z., Qu, C. K., Albanese, S., Lima, A., Cicchella, D., Hope, D., Cerino, P., Pizzolante, A., Zheng, H., Li, J. J., De Vivo, B., 2020. Investigation of polycyclic aromatic hydrocarbons in soils from Caserta provincial territory, southern Italy: Spatial distribution, source apportionment, and risk assessment. Journal of Hazardous Materials, 383: 121158.

Qu, C. K., Albanese, S., Lima, A., Hope, D., Pond, P., Fortelli, A., Romano, N., Cerino, P., Pizzoante, A., De Vivo, B., 2019. The occurrence of OCPs, PCBs, and PAHs in the soil, air, and bulk deposition of the Naples metropolitan area, southern Italy: Implications for sources and environmental processes. Environment International, 124: 89-97.

Sambrotto, R. N., Goering, J. J., McRoy, C. P., 1984. Large yearly production of phytoplankton in the 
Western Bering Strait. Science, 225(4 667): 1 147-1 150.

Shaw, M., Mueller, J. F., 2009. Time integrative passive sampling: how well do chemcatchers integrate fluctuating pollutant concentrations? Environmental Science \& Technology, 43(5): $1443-1448$.

Shen, H. Z., Huang, Y., Wang, R., Zhu, D., Li, W., Shen, G. F., Wang, B., Zhang, Y. Y., Chen, Y. C., Lu, Y., Chen, H., Li, T. C., Sun, K., Li, B. G., Liu, W. X., Liu, J. F., Tao, S., 2013. Global atmospheric emissions of polycyclic aromatic hydrocarbons from 1960 to 2008 and future predictions. Environmental Science \& Technology, 47(12): 6 415-6 424.

Stabeno, P. J., Van Meurs, P., 1999. Evidence of episodic on-shelf flow in the southeastern Bering Sea. Journal of Geophysical Research-Oceans, 104(C12): 29 715-29 720.

Stuer-Lauridsen, F. 2005. Review of passive accumulation devices for monitoring organic micropollutants in the aquatic environment. Environmental Pollution, 136(3): 503-524.

Tucca, F., Luarte, T., Nimptsch, J., Woelfl, S., Pozo, K., Casas, G., Dachs, J., Barra, R., Chiang, G., Galban-Malagon, C., 2020. Sources and diffusive air-water exchange of polycyclic aromatic hydrocarbons in an oligotrophic North-Patagonian lake. Science of the Total Environment, 738: 139838.

Venier, M., Hung, H., Tych, W., Hites, R. A., 2012. Temporal trends of persistent organic pollutants: A comparison of different time series models. Environmental Science \& Technology, 46(7): 3 9283934.

Wania, F., Shunthirasingham, C., 2020. Passive air sampling for semi-volatile organic chemicals. Environmental Science-Processes \& Impacts, 22(10): 1 925-2 002.

Woodgate, R. A., Aagaard, K., Weingartner, T. J., 2005. A year in the physical oceanography of the Chukchi Sea: Moored measurements from autumn 1990-1991. Deep-Sea Research Part IITopical Studies In Oceanography, 52(24-26): 3 116-3 149.

Wu X. W., Wang, Y., Zhang, Q. N., Zhao, H. X., Yang, Y., Zhang, Y. W., Xie, Q., Chen, J. W., 2019. Seasonal variation, air-water exchange, and multivariate source apportionment of polycyclic aromatic hydrocarbons in the coastal area of Dalian, China. Environmental Pollution, 244: 405413.

Yunker, M. B., Macdonald, R. W., Vingarzan, R., Mitchell, R. H., Goyette, D., Sylvestre, S., 2002. PAHs in the Fraser River basin: A critical appraisal of PAH ratios as indicators of PAH source and composition. Organic Geochemistry, 33(4): 489-515.

Yunker, M. B., Macdonald, R. W., Snowdon, L. R., Fowler, B. R., 2011. Alkane and PAH biomarkers as tracers of terrigenous organic carbon in Arctic Ocean sediments. Organic Geochemistry, 42(9): 1 109-1 146.

Zhao, W. L., Cai, M. G., Adelman, D., Khairy, M., August, P., Lohmann, R., 2018. Land-use-based sources and trends of dissolved PBDEs and PAHs in an urbanized watershed using passive polyethylene samplers. Environmental Pollution, 238: 573-580.

Zhong, G. C., Xie, Z. Y., Cai, M. H., Moeller, A., Sturm, R., Tang, J. H., Zhang, G., He, J. F., Ebinghaus, R., 2012. Distribution and air-sea exchange of current-use pesticides (CUPs) from East Asia to the high Arctic Ocean. Environmental Science \& Technology, 46(1): 259-267. 

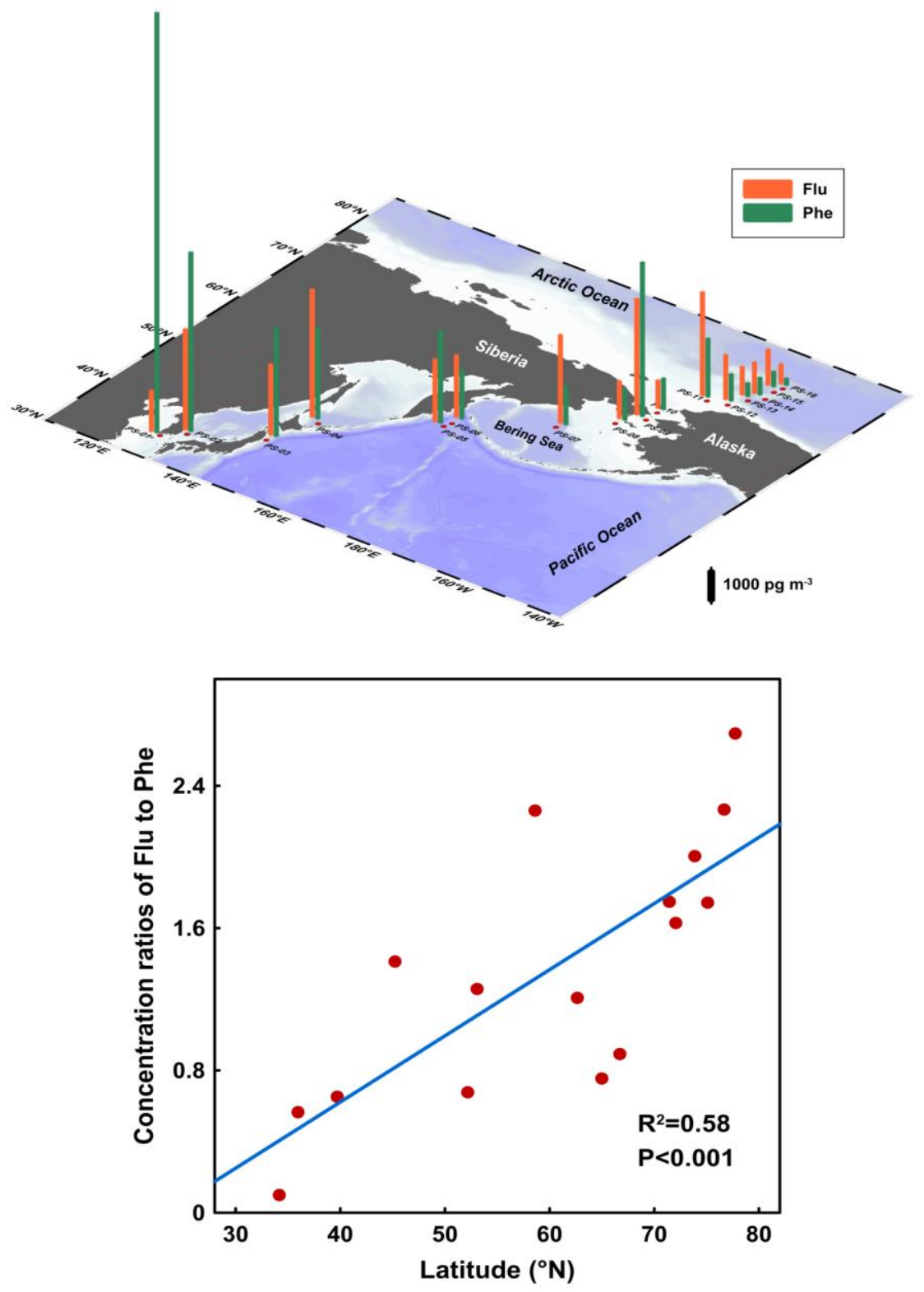

614 Fig. 1. The gaseous concentration distribution of Flu and Phe along the cruise transect 615 (the figure above), and the ratios of Flu to Phe as a function to latitude (the figure below). (The domination of Flu and Phe presented in Fig. S3) 

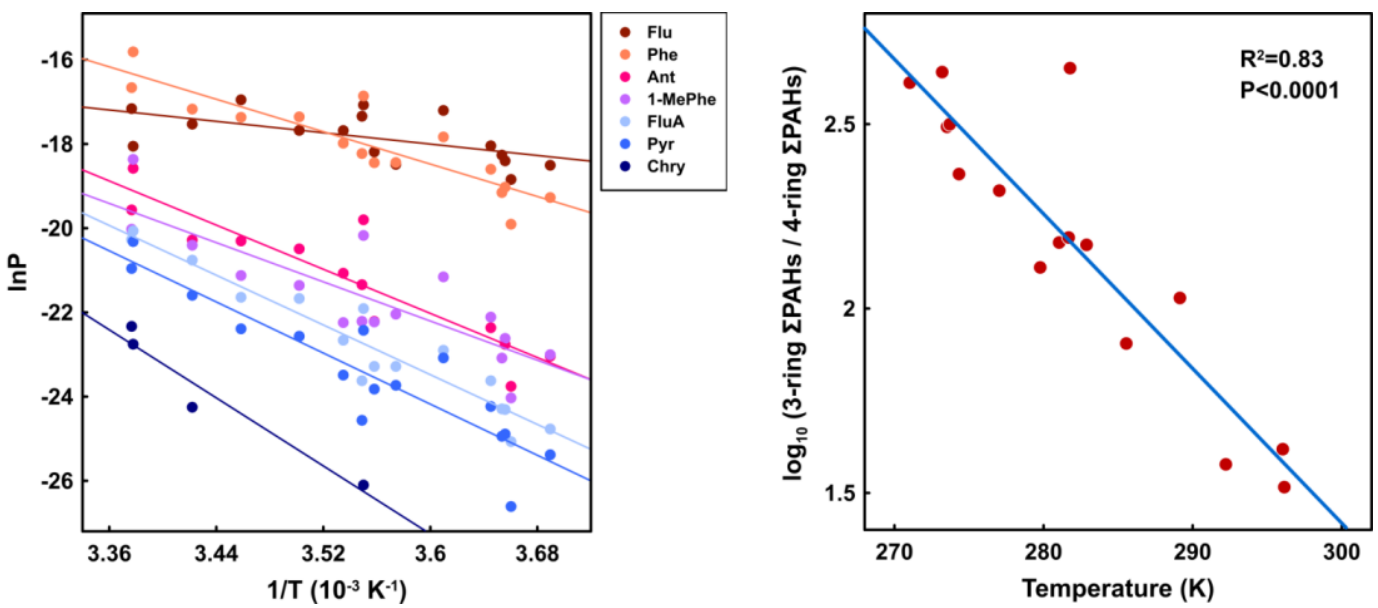

Fig. 2. The partial pressure of PAH congeners as a function of water temperature (left), and the ratios of the sum of three-ring PAHs to four-ring PAHs as a function of air temperature (right).

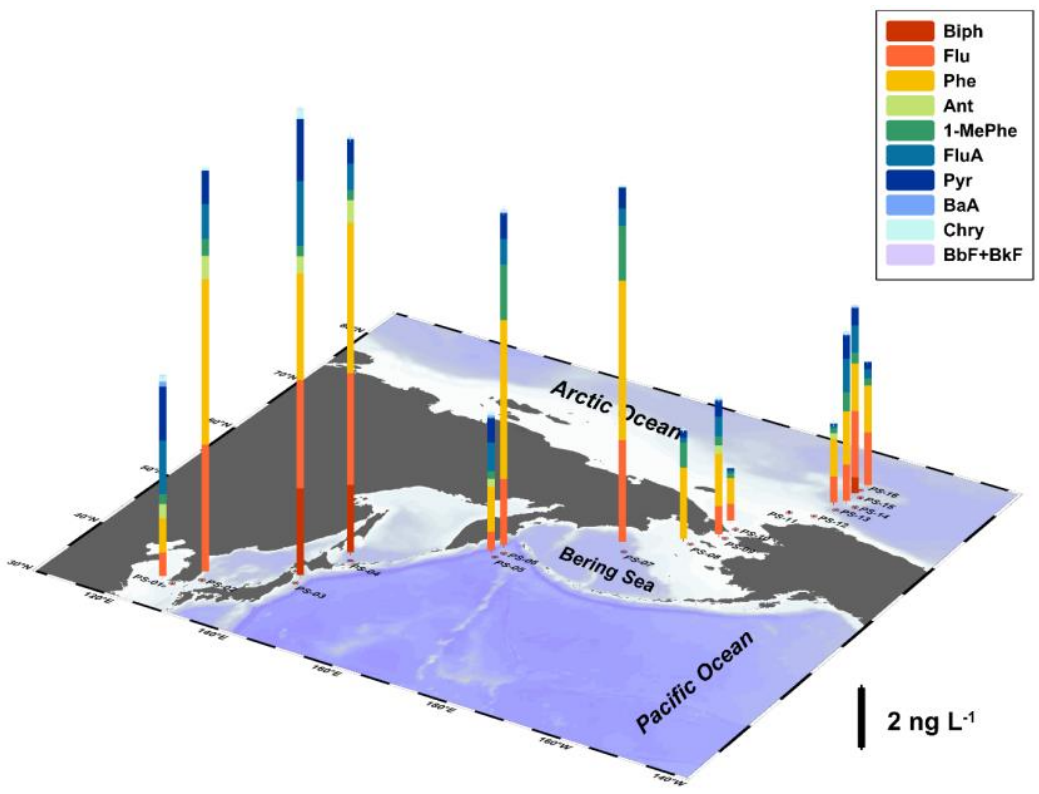

Fig. 3. The PAH concentrations in surface seawater along the cruise transect. 


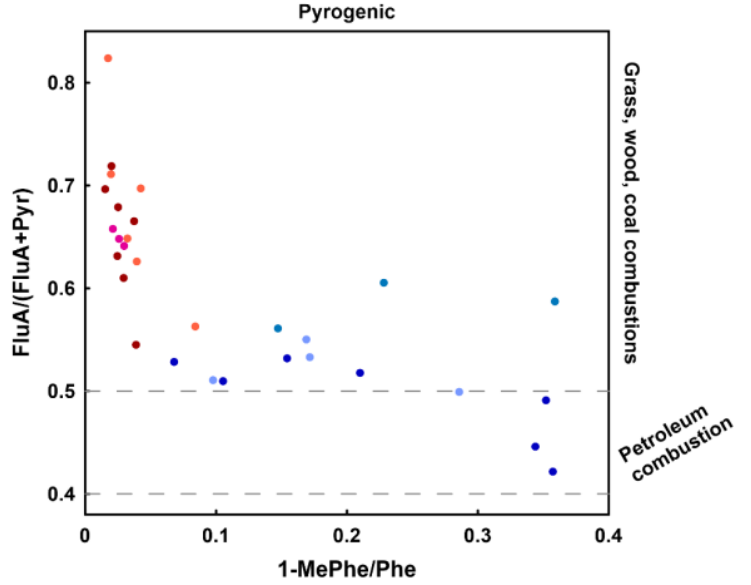

Fig. 4. Results of PAH diagnostic ratios of MePhe/Phe and FluA/(FluA+Pyr) (left),

628 and PCA (right) for samples in seawater (dots in blue) and atmosphere (dots in red). 

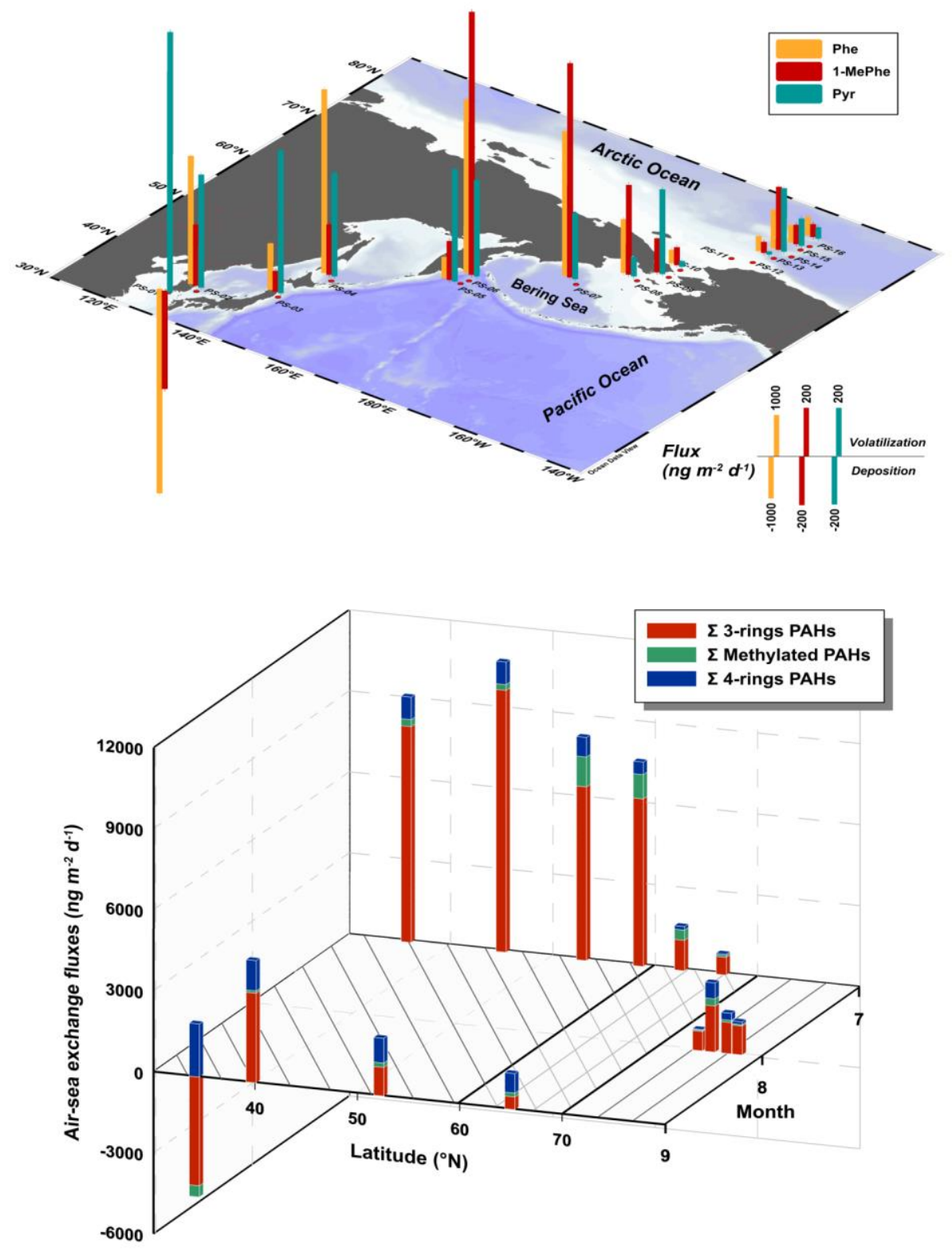

630 Fig. 5. The distribution of PAH air-sea exchange fluxes, and their monthly changes. 